\title{
UNDERSTANDING THE STRUCTURAL BEHAVIOR OF HISTORICAL BUILDINGS THROUGH ITS CONSTRUCTIVE PHASE EVOLUTION USING H-BIM WORKFLOW
}

\author{
Alfredo CALİ $\mathbb{B}^{*}$, Poliana DIAS DE MORAES ${ }^{\circledR}$, Ângela DO VALLE® \\ Department of Civil Engineering, Federal University of Santa Catarina, Florianópolis, Brazil
}

Received 29 September 2019; accepted 14 January 2020

\begin{abstract}
Knowledge is fundamental to understand the key characteristics of a heritage building. Furthermore, constructive analysis of a historical construction is central to research into its structural behavior. This work aims to increase the knowledge level of a historical construction by the understanding of the constructive evolution through Historical-Building Information Modeling (H-BIM) workflow. The research proposes a multidisciplinary approach applicable to the field of historical constructions, which is resumed in the followings steps: historical-critical analysis, material and soil characterization, data organization through H-BIM, qualitative static and dynamic structural analysis, validation of the results. The building of Quartel da Tropa - located in Florianópolis, Brazil - is used as a practical case study to show how the proposed research can be adapted to historical buildings. Such an impressive eighteen-century masonry construction is the largest troop barracks among Brazilian fortifications. The proposed approach allows the creation of a structural model from the architectural model with fewer uncertainties and less simplification, improving the knowledge path of historical constructions and its structural assessment. The historical-critical analysis and the H-BIM allow managing and presenting of the information useful to the understanding of the constructive phase evolution of a historical building.
\end{abstract}

Keywords: H-BIM, structural analysis of historical constructions, knowledge path of cultural heritage, historical-critical analysis.

\section{Introduction}

The knowledge path of a historical construction is a fundamental part of a methodology introduced in the Italian Guidelines for evaluation and mitigation of seismic risk to Cultural Heritage (MIBAC, 2017). It allows assessing the level of safety against seismic actions and designing interventions aimed at the protection of historical structures. The document underlines the crucial role of the knowledge phases in the process of understanding of the structural behavior of heritage buildings, providing a fundamental approach to assess the structural risk (MIBAC, 2017). Such an approach is developed to analyze the key characteristics of heritage buildings. It helps to define interpretive models by conducting both a qualitative evaluation of a building structural behavior and a quantitative structural analysis (MIBAC, 2017; Vandesande \& Van Balen, 2018; Ioannides et al., 2016). The level of reliability of the interpretive model is strongly related to the level of details (LoDs) of the model (Biagini et al., 2016) and the available data (MIBAC, 2017; Vandesande \& Van Balen,
2018; Ioannides et al., 2016). The LoDs and the available data are deeply related to the definition of the main constructive phases of the building. The level of knowledge of these types of constructions goes through the constructive investigation and the assessment of structural characteristics. It represents a challenge that requires surveys, insitu or laboratory tests and analysis that can be laborious and expensive (Gentile \& Saisi, 2007; Mastrodicasa, 2012; Gentile et al., 2015; Oreni et al., 2017). Understanding how and which modifications led the 'as-designed' project to its 'as-built' state is one of the main phases in the knowledge path of the building itself. Analyzing the reasons behind the evolution and the progress of building construction is necessary to understand the 'as-built' state. When a restoration project is developed, quick and easy access to all needed information can be difficult. In the case of buildings with historical value, analyzing the project sources and documents that describe the structural evolution is much broader and more difficult to interpret than in the

${ }^{*}$ Corresponding author. E-mail: alfredo.cali@posgrad.ufsc.br 
case of contemporary structures. In the proposed work, this identification is obtained by a historical-critical analysis of the documental sources of the building (MIBAC, 2017; ReLUIS, 2010). Often the lack of historical information does not provide data on the material characteristics nor the information required to understand the reasons for those interventions. In this research, the authors want to propose an approach for the improvement of the knowledge of the historic building through the analysis of the constructive phase evolution.

Modern software allows the creation of interactive database collectors for the elaboration of architectural projects, including structural characteristics. Such software is based on the Building Information Modeling (BIM) methodology, which describes collaborative processes for production and management of structured electronic information (Antonopoulou \& Bryan, 2017). The power of this methodology turns it widely used by professionals in various fields. The use of BIM in new projects has been a regular practice for several years (Eastman et al., 2011). In recent years, BIM has been extensively employed for academic and research proposal (Murphy, 2012). However, finding BIM applications in the restoration of buildings with historical value than in contemporary ones is less common (Volk et al., 2014). This is mainly due to the effort required to digitize acquired data, often incomplete, fragmented and not up-to-date for comprehensive and complete modeling (Volk et al., 2014). The lack of information implies a low level of details (LoDs), which can be increased by the use of Building Information Modeling. In recent years, BIM has been used in restoration processes of historical buildings (Antonopoulou \& Bryan, 2017), due to its excellent performance during the phases of definition and description of the building constructive evolution, the maintenance of its elements and its risk assessment. In the heritage buildings information modeling (H-BIM), structural evaluation of the construction is fundamental, and it goes throughout the different building phases interpretation (Antonopoulou \& Bryan, 2017). The interoperability of the available software allows the use of more appropriate structural computing software, which in turns permits more precise modeling and provides more appropriate methods of analysis, such as the modal and dynamic analyses (Antonopoulou \& Bryan, 2017). Despite many BIM and H-BIM researches being analyzed, they are mostly focused on the geometrical description of the 'as-built' configuration of heritage building through laser scanning and photogrammetry or on the organization of the data sources. Few examples of H-BIM in combination with structural FEM analysis were found (Murphy, 2012; Barazzetti et al., 2015; Chi et al., 2015; Dore et al., 2015; Oreni et al., 2017) and even fewer considering the heritage constructive phases for the structural assessment of the building (Crespi et al., 2015). An extensive review on the H-BIM can be found in the work of Bruno et al. (2018). These authors pointed out useful solutions to fill the scientific gaps in the integration between BIM with diagnostics and monitoring for structural reinforcement.
Some of these points include dynamic analysis of the modal parameters, i.e. frequencies and modal shapes assessment, and evaluation of health and safety status of the structures through Finite Element Analysis (Bruno et al., 2018). The state of art of the H-BIM literature confirmed that there is still a need for research in the scientific field of heritage structural assessment (Bruno et al., 2018; Pocobelli et al., 2018).

In the heritage analysis field, linear elastic analysis is commonly used as an auxiliary tool assisting in the diagnosis of large masonry structures (Roca et al., 2010). While its application to masonry structures is widely used, it does not consider the non-linear response and other essential features of real masonry behavior. Due to the high level of uncertainties about the non-linear properties of the materials, in the proposed research linear elastic analysis was chosen as a qualitative approach to the structural behavior assessment (Roca et al., 2010). Such an approach leads to suppose the following hypotheses. Mechanical behavior of materials are linear elastic, displacements of the structure in the deformed configuration are small and the structural constraints are bilateral and do not depend on the entity of the acting load (Del Piero, 1989; Roca et al., 2010). Modal analysis was used to evaluate the evolution of construction behavior in the main directions of the structure (Meli \& Peña, 2004). The static analysis was developed to assess where the structural elements reach top out-of-plane displacement and base compressive stress.

The objective of this work is to improve the knowledge path of a historical building through the H-BIM workflow, understanding the influence of the constructive phases in the structural behavior of a historical building and investigating the possible reasons for such modifications. Such an approach also leads to suggest possible special cares for future structural intervention proposals. Furthermore, one of the aims of this research is to analyze the accuracy of the H-BIM workflow during the process between architectural and structural modeling of a heritage built. The H-BIM model can be obtained directly from point clouds - generated by laser scanning or photogrammetry processing, or from $2 \mathrm{D}$ technical drawings. In the proposed workflow, the authors chose the last option to allow extending the proposed workflow to the general case where only $2 \mathrm{D}$ drawings are available.

The proposed workflow can be resumed in the following steps: 1) historical-critical analysis of the data source, 2) material and soil characterization, 3) data organization through Historical Building Information Modeling ( $\mathrm{H}-$ BIM), 4) qualitative dynamic and static structural analysis, 5) elaboration of the results. The proposed paper intends to increase the level of knowledge of a historical building, aiming at understanding the evolution of the constructive phases through the use of Historical Building Information Modeling (H-BIM) (Antonopoulou \& Bryan, 2017) and finite element method analysis (Zienkiewicz \& Taylor, 2000; Bathe, 2016). The heritage building of the Quartel da Tropa - belonging to the fortress of Anhatomirim Island (SC), Brazil - was chosen to apply the proposed approach. 


\section{The knowledge path of historical construction}

A historical masonry structure is selected as an example to apply the proposed multidisciplinary approach, the Quartel da Tropa (literally Troop Barracks), that is the largest among Brazilian fortifications (Figure 1). The construction is one of the main buildings of the Fortress of Santa Cruz, located on Anhatomirim Island in the municipality of Governador Celso Ramos, State of Santa Catarina, Federal Republic of Brazil. The construction was designed by the Portuguese military engineer José da Silva Paes. In the eighteenth century, the fortress belonged to one of the cornerstones of the triangular defense system, still formed by the Fortresses of São José da Ponta Grossa and Santo Antônio de Ratones. This system was designed to protect the northern side of Santa Catarina Island from foreign attacks, mainly from Spain, and consolidate the Portuguese occupation of Southern Brazil in the eighteenth century. The as-designed project demonstrates the influence of Renaissance architecture (Tonera \& Fragoso, 2013) (Figure 2a).

\subsection{Historical-critical survey of the constructive evolution}

The evaluation of constructive evolutions and the construction identification were obtained through the historical-critical analysis of the documental sources (Tonera \&
Fragoso, 2013; Calì et al., 2019). Such evaluation helps to understand the structural performances of the construction and the possible modifications caused by each constructive phase (Magenes \& Menon, 2009). In-situ measurements and visual inspections were carried out by the authors. Such sources, together with the evaluation of the existing geometrical surveys (Tonera \& Fragoso, 2013) and the historical-critical analysis (Calì et al., 2019), allow the defining of the main characteristics of this heritage built and summarizing them in a Heritage Building Information Model (H-BIM). The structure - length $66.8 \mathrm{~m}$, width $9.85 \mathrm{~m}$, height $10.5 \mathrm{~m}$ - is characterized by the presence of masonry arches in the longitudinal direction (Figure 3a) - north-east façade - and in the transversal direction (Figure $3 \mathrm{~b}$ ), connecting the thick slope-shaped retaining wall to the main façade (Figure $3 \mathrm{c}$ ). A central slope-shaped masonry element and buttresses were introduced in the north-east façade along with the constructive history of the building (Figure 3e), but no information about the reasons of such intervention was found in the documentary research (Tonera \& Fragoso, 2013). The structure had two symmetrical mezzanines at the opposite side of the main façade (Figure 4), but in the 'as-built' configuration (Figure $4 \mathrm{~d}$ ), only the mezzanine of the northwest part still exists. The access to such mezzanines was in the partially buried lateral façades (Figure 3f). The first

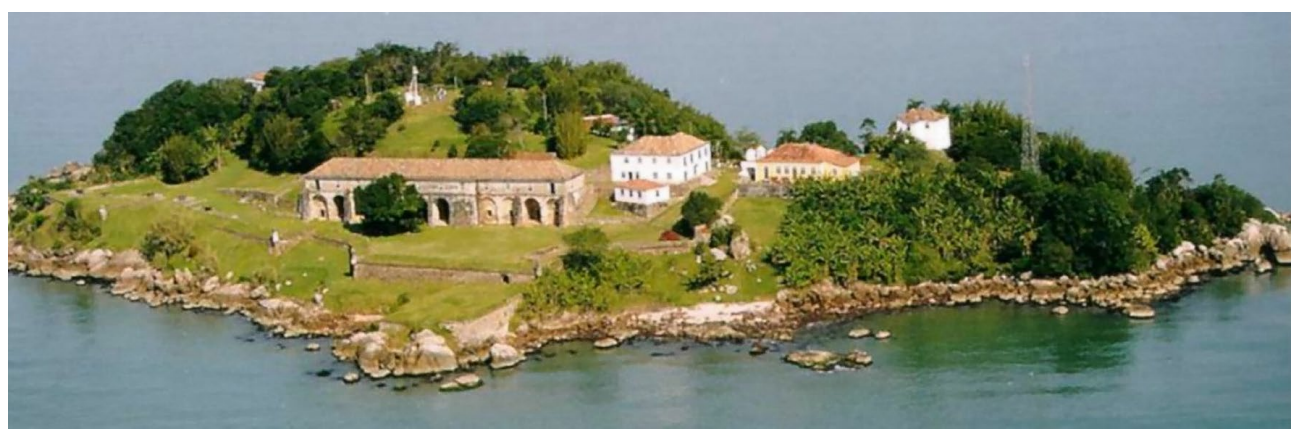

Figure 1. Overall view of the fortress of Anhatomirim Island, Santa Catarina, Brazil. Source: Backert \& Sartori architecture (Tonera \& Fragoso, 2013)

a) As-dcsigned drawing of the north-east facade

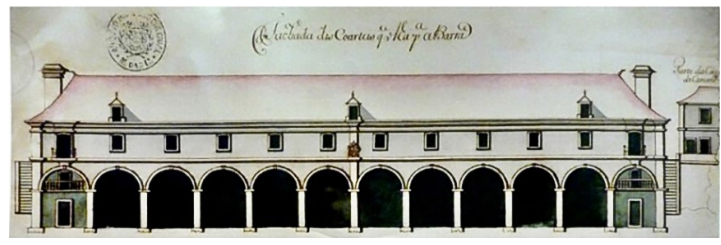

c) Second floor plan

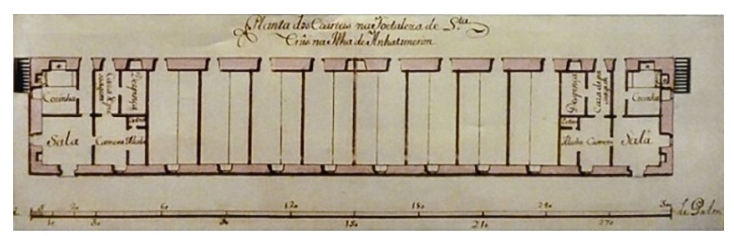

b) Ground floor plan

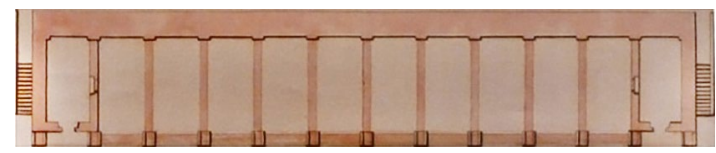

d) Mezzanine floor plan

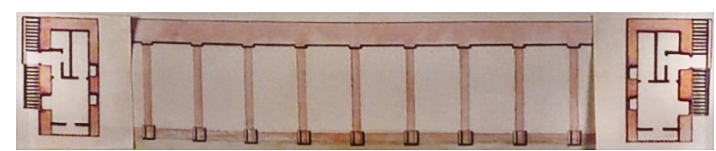

Figure 2. 'As-designed' representation of the Quartel da Tropa: a) north-east façade; b) ground floor plan; c) second-floor plan; and d) mezzanine floor plan. Source: Arquivo Histórico Ultramarino, Lisbon (Tonera \& Fragoso, 2013) 
level of the south-west façade is totally buried, and thick slope shaped wall retain the soil action (Figure 3c).

During its lifecycle, the spatial configuration of the building was modified according to the different service functions. In the 'as-designed' configuration, the construction was conceived as military troop barracks, later on, it was used as a military hospital, jail and in the last years as a museum (Tonera \& Fragoso, 2013). In terms of structural behavior, functional changes have also led to a different distribution of dead and alive loads during the construction life cycle, which hinders a global understanding of the state of stress and displacement of the 'as-built' configuration. The historical-critical analysis will be useful to consider those considerations in further research stages.

Historical-critical analysis of the documental researches and existing geometric surveys (Tonera \& Fragoso, 2013) allow creating the H-BIM model where the build- ing constructive evolution through four main phases are represented (Tonera \& Fragoso, 2013). According to the historic researches in the archives of the Instituto de Patrimônio Histórico e Artístico Nacional (IPHAN), the slope-shaped masonry element and the buttresses of the north-east façade are not represented in the original drawings of 1747 (Tonera \& Fragoso, 2013). Such elements are represented in further drawings and documents (Tonera \& Fragoso, 2013). It is possible to suppose that they were implemented in further constructive phases: the central masonry element was probably introduced in 1760 and the buttresses in 1843 (Tonera \& Fragoso, 2013). The analysis of the documental sources also shows that, during the restoration of 1970, the wooden horizontal structural elements underwent profound modifications (Tonera \& Fragoso, 2013) (Figures 3b, 3e and 3g), according to a trend also found in other architectural heritage sites
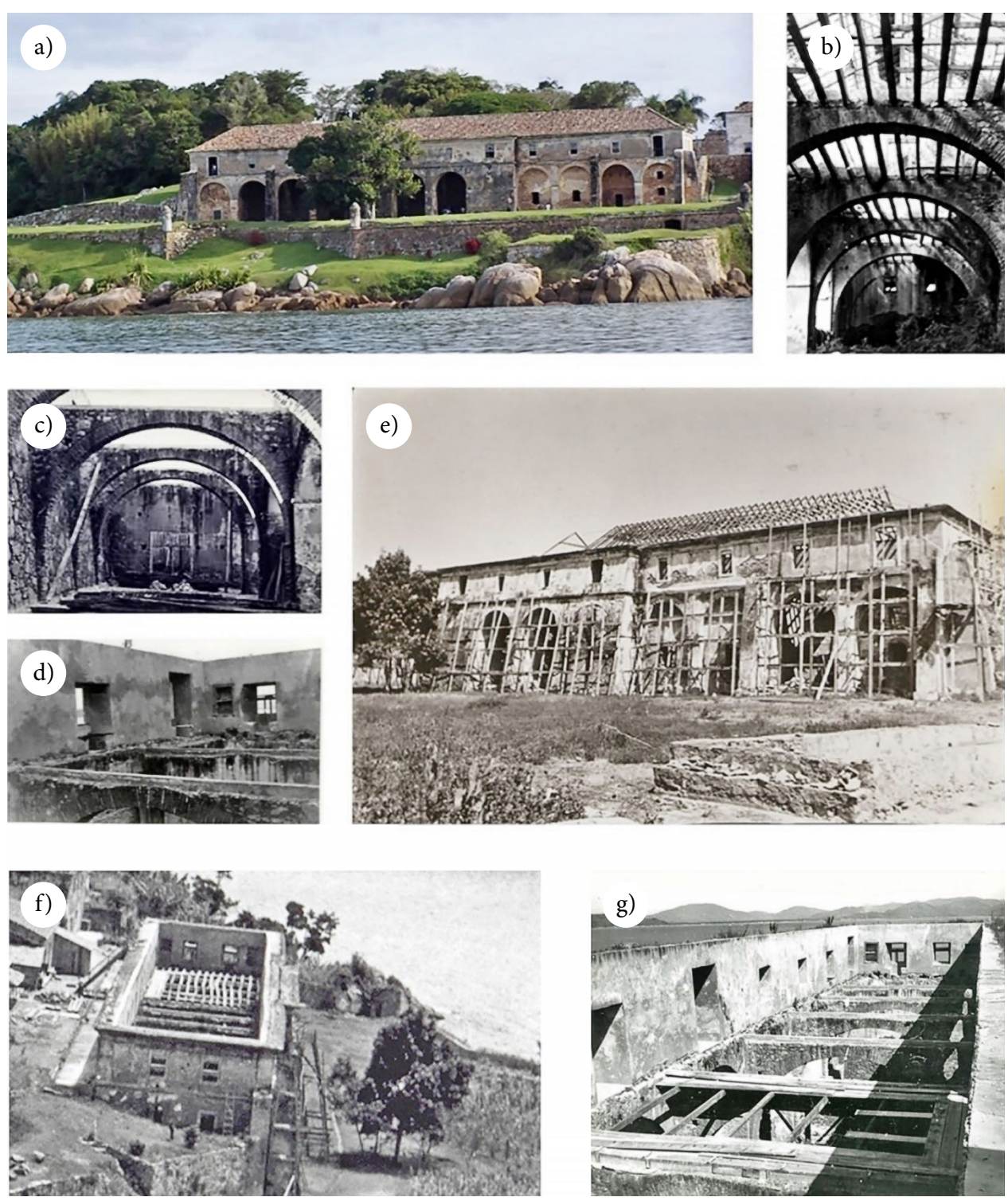

Figure 3. Quartel da Tropa (a) in the 'as-built' configuration after the 1970s restorations (b, c, d, e) where the simple trussed roof structure (b) was replaced with a collar tie beam (e) and concrete beams (d) were introduced on the masonry arches (c) and (g); three sides of the construction are partially buried (f) (Tonera \& Fragoso, 2013) 
in Brazil (Pereira, 2007). The roof structure was simply trussed, with king post and struts (Figure $3 \mathrm{~b}$ ). It was replaced with trusses with a collar tie beam (Figure 3e). In the same restoration of 1970, the beams of the wooden slabs, which were fixed in the masonry walls (Figure $3 b$ ), were substituted by simply supported beams resting on new reinforced concrete beams, leaning on the masonry arches (Figure 3b).

Each of these phases is represented in the H-BIM model (Figure 4). Phase 1 represents the 'as-designed' project of 1747 (Figure 4a), Phase 2 shows the central masonry slope-shaped element of 1760 (Figure $4 \mathrm{~b}$ ), Phase 3 represents the introduction of buttresses of 1843 (Figure 4c) and Phase 4 corresponds to the 'as-built' construction, after the restoration interventions of 1970 (Figure 4d). Indeed, during its history, the Quartel was used in different ways, for example as a military jail or as military hospital (Tonera \& Fragoso, 2013), meaning that the distributive configuration of the spaces was modified according to the function it had to supply (Figure 4e). Those different functions lead to different load values and distributions that modify the structural behavior of the elements.

\subsection{Material and soil characterization}

An appropriate approach to structural risk assessment involves an adequate definition of material characteristic parameters through comprehensive research campaigns (MIBAC, 2017; Vandesande \& Van Balen, 2018; Ioannides et al., 2016). However, simulating the case where researchers do not have the possibility to develop such extensive experimental campaigns, simplifications of the material behavior had to be adopted. Material characteristics were estimated from experimental results (Terezo, 2005; Geotechnical Mapping Laboratory of Federal University of Santa Catarina [LAMGEO], 2018), national standards (ABNT, 2004; NTC, 2008) or obtained from proved scientific literature (Zenid, 2009; Ross, 2010; Rocco Lahr et al., 2015; Ferrito et al., 2016). Despite Brazilian research studies on this type of masonry structures being found (Arash, 2012; Carvalho et al., 2014), large variability in the results was observed (Carvalho et al., 2014). For these reasons, material properties were implemented according to the suggested values of the Italian Standard (NTC, 2008) and proved scientific researches in this field (Gesualdo \&
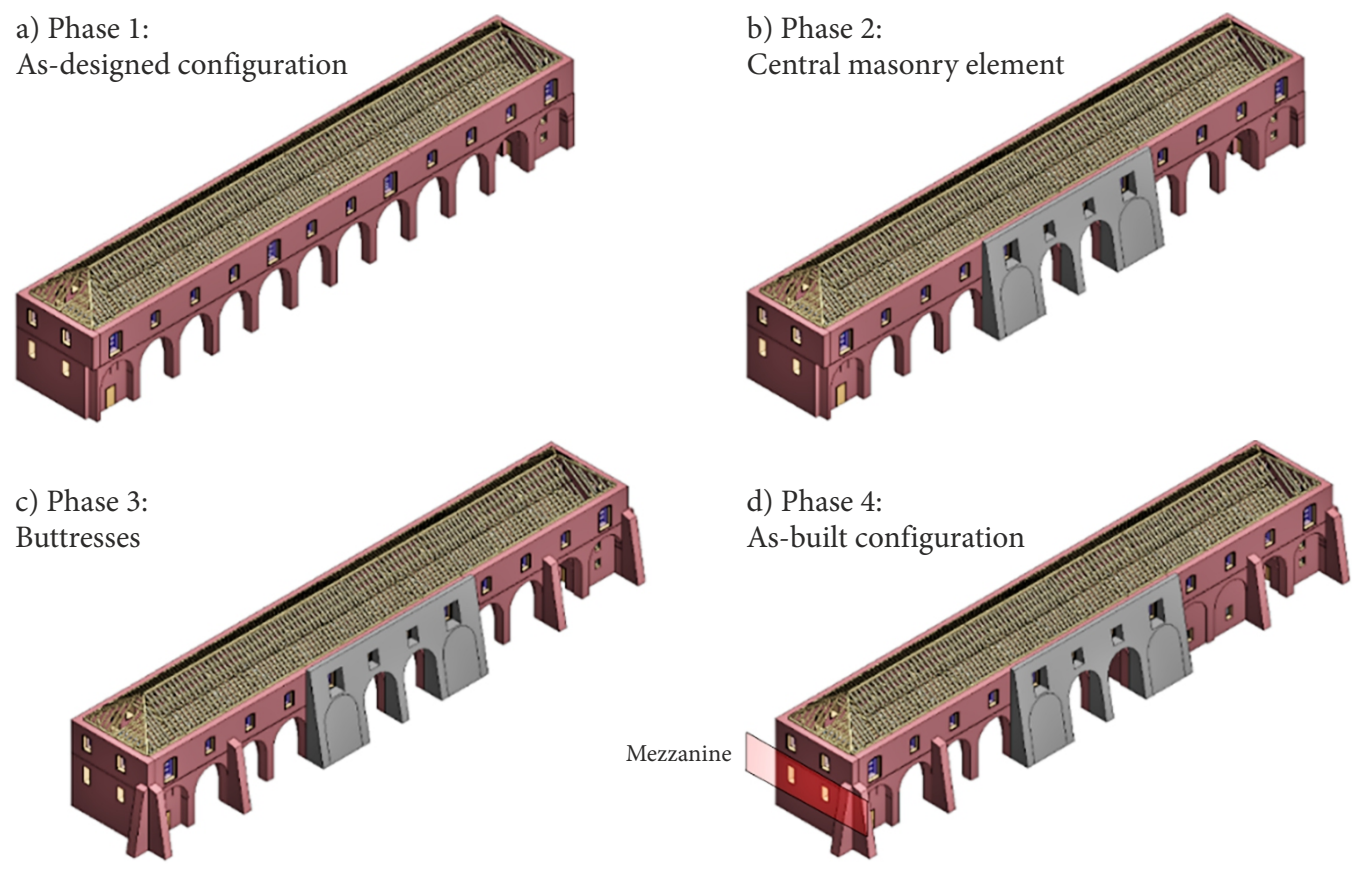

c) Plan of the ground floor of the Quartel da Tropa

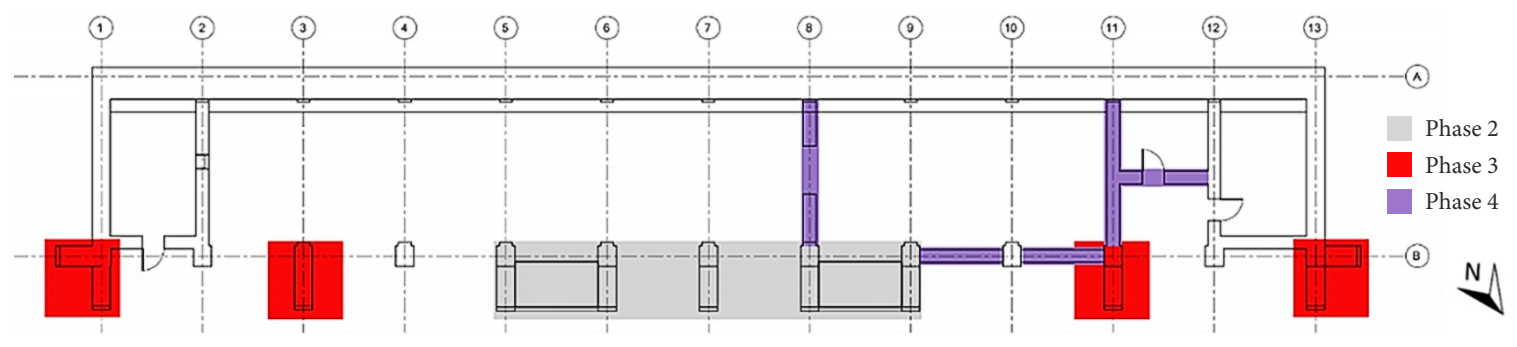

Figure 4. Constructive evolution in the H-BIM: (a) 'as-designed' project; (b) the introduction of the central masonry element; (c) the introduction of the buttresses; (d) 'as-built' project; (e) ground-level plan according to the constructive evolution 
Nunziante, 2005; Roca et al., 2010). Such references allow the adopting of an average value $1.40 \mathrm{MPa}$ - interval between 1.00 and $1.80 \mathrm{MPa}$ - for the compressive strength of the masonry structures (NTC, 2008). The compressive strength will be considered to check if the results obtained from the static analysis are sufficiently distant from these values, meaning that the linear static behavior also has a physical meaning. Concerning the wooden structure, a geometric and physical survey confirms that there are several types of wooden species in the different structural elements (Terezo, 2005). Despite this heterogeneity, most of the wooden beam elements are made of the same wood species, Peroba rosa (technically known as Aspidosperma pirycollum) (Terezo, 2005). Experimental tests on the soil were carried out by the authors (LAMGEO, 2018), with the aims of increasing the understanding of the historical construction and its environment (MIBAC, 2017). Direct shear tests, granulometric analysis, and humidity test were carried out to obtain cohesion $C$, friction angle $\Phi$, density soil $\gamma$. Such tests suggest that the soil type is red yellow podzols and the soil lithology is granitic rock type which is considered as cohesive soil. It should be noted that such characterization is developed to assess the contribution of the soil in terms of horizontal load action and it will be presented in Section 2.1.2 of this work. The material and the soil characteristics implemented in the model are summarized in the following Table 1.

Table 1. Characteristics of the physical and mechanical parameters

\begin{tabular}{|l|c|c|c|c|c|}
\hline & $E[\mathrm{MPa}]$ & $v$ & $\gamma\left[\mathrm{kN} / \mathrm{m}^{3}\right]$ & $C[\mathrm{kPa}]$ & $\Phi\left[{ }^{\circ}\right]$ \\
\hline $\begin{array}{l}\text { Masonry } \\
\text { structures }\end{array}$ & 1309.50 & 0.25 & 19.00 & - & - \\
\hline $\begin{array}{l}\text { Wooden } \\
\text { structures }\end{array}$ & 10500.00 & 0.27 & 6.38 & - & - \\
\hline $\begin{array}{l}\text { Concrete } \\
\text { beams }\end{array}$ & 18435.00 & 0.20 & 25.00 & - & - \\
\hline Soil & - & - & 15.50 & 14.70 & 18.40 \\
\hline
\end{tabular}

\section{Numerical model}

The creation of the H-BIM model of the Quartel da Tropa begins with the analysis of the available information. The main source is a comprehensive geometric survey of the construction, including the pathology survey (Tonera \& Fragoso, 2013), the identification of the wooden structures (Terezo, 2005) and experimental test on the soil (LAMGEO, 2018). The existing 2D CAD drawings (Tonera \& Fragoso, 2013) represent the main sources of the architectural H-BIM model. The software used to model the building is Autodesk Revit ${ }^{\circledR}$ (Autodesk Inc., 2012b). This software allows for the creation of structural analytical models - elaborated from the architectural model - and analyzing it through default structural tools. Furthermore, the analytical model can be exported to other structural analysis software. In the proposed workflow, the analytical model was exported in Autodesk Robot Structural
Analysis $^{\circledast}$, software based on the Finite Element Method (Zienkiewicz \& Taylor, 2000; Bathe, 2016). In this phase of analysis, materials are considered homogeneous and isotropic. As developed in the research of Haciefendioğlu et al. (2016), linear elastic behavior is assumed, and stiffness degradation is neglected.

\subsection{Finite element model}

The BIM software Revit ${ }^{\circledast}$ simplifies the structural analytical model representing walls by their middle planes and beams by their longitudinal axes. The generation of the finite element model was developed in $\operatorname{Robot}^{\circledast}$ (Autodesk, Inc., 2015a). It allows the user to modify the finite elements meshing discretization, that in Revit ${ }^{\circledR}$ is not customizable (Autodesk Inc., 2012b). Such H-BIM workflow allows updating both architectural and structural models by the use of compatible software. The modifications introduced in one of the two software can be exported to the other one. In the FEM model, the wall middle planes are discretized by thick-shell meshes, which are defined as 4-node quadrilateral elements $\left(Q_{4}\right)$. This type of mesh is defined according to the discrete Kirchhoff-Mindlin element based on Mindlin-Reissner (Discrete KirchhoffMindlin Quadrilateral, DKMQ) plate theory and assumed shear strain fields (Ho-Le, 1988; Katili, 1993). The beams are modeled as linear bar elements, with 6 degrees of freedom at each node. Regarding the behavior of $Q_{4}$ elements in connection with bar elements - perpendicular to the plane of FE (in direction of drilling rotation), pinned connections are generated.

A fundamental characteristic of such H-BIM workflow is that the compatibility between the two software allows modification of the FEM model and consequently updating the H-BIM model at a later stage (Autodesk Inc., $2012 b)$. In the FEM software Robot ${ }^{\oplus}$, the main methods of finite element mesh discretization are Delaunay (Ho-Le, 1988) and Coons (Coons, 1967; Provatidis \& Kanarachos, 2000). As already pointed out, the type of mesh element automatically chosen during the exportation from Revit ${ }^{\circledast}$ to Robot ${ }^{\circledast}$ is the shell element (Autodesk Inc., 2012b). Furthermore, due to the complexity of the analytical model, the process of mesh refinement is important to validate the finite element model and to obtain consistent results. However, in this research, the number of degrees of freedom (DoF) of the model was considered as a fundamental parameter. A good balance between mesh quality (Kolcun, 1999) and DoF allows the creation of a consistent analytical model that can be analyzed without a high computational effort.

\subsubsection{Definition and calibration of the mesh}

In the proposed work, several models are analyzed to define and calibrate the mesh. The chosen parameters defining each model are mesh type and quality, size and number of finite elements, number of degrees of freedom and time of elaboration of linear elastic analysis. Robot ${ }^{\oplus}$ provides two dimensionless parameters to evaluate the 
global mesh quality coefficient. The quality of all mesh elements, $Q_{1}$ (Eqn (1)), where values of elements (triangles, quadrilaterals) are averaged (Autodesk Inc., 2015b) and the weighted quality of all mesh elements, $Q_{2}$ (Eqn (2)), where weighted values - the mesh element area considered as weight - of elements (triangles, quadrilaterals) are averaged (Autodesk Inc., 2015b).

$$
\begin{aligned}
& Q_{1}=\frac{1}{n} \sum_{k=1}^{n} \alpha_{i} ; \\
& Q_{2}=\frac{1}{\Omega} \sum_{k=1}^{n} \Omega_{i} \alpha_{i},
\end{aligned}
$$

where $\alpha_{i}$ is the mesh quality of each element calculated according the Eqn (3), $\Omega_{i}$ the area of the $i$-th element and $\Omega$ the total area of the mesh elements, $\Omega_{i}$ the area of each $i$-element, $n$ number of mesh element.

Calculation of $\alpha_{i}$ coefficients is done for each triangle: $\left\{\alpha_{1}, \alpha_{2}, \alpha_{3}, \alpha_{4}\right\}=\{\alpha(A B C), \alpha(A C D), \alpha(A B D), \alpha(B C D)\}$. Any quadrilateral $A B C D$ is divided into 4 overlapped triangles $(\mathrm{ABC}, \mathrm{ACD}, \mathrm{ABD}$, and $\mathrm{BCD})$. Once these coefficients are calculated, the quality coefficient is calculated by Eqn (3) (Autodesk Inc., 2015b):

$$
\alpha(A B C)=2 \sqrt{3} \frac{\overrightarrow{C A} \times \overrightarrow{C B} \cdot \vec{n}}{\|C A\|^{2}+\|A B\|^{2}+\|B C\|^{2}} .
$$

The mesh quality parameters $Q_{1}$ and $Q_{2}$ increase according to the reduction of the element size (Figure 5). However, as long as the element size decreases the number of degrees of freedom grows exponentially. It causes an increase in the computational effort of the analysis, even in the phases of linear elastic analysis. The use of the Coons (1967) element method was selected because the time analysis is almost 3 times less than the Delaunay method. The element size $0.3 \mathrm{~m}$ was chosen due to the combination of convergence of the results, good mesh quality $\left(Q_{1}=0.96 ; Q_{2}=0.96\right)$ (Figure 5$)$ and a number of degrees of freedom (164358) that still ensures the quickness of the linear elastic analyses.

\subsubsection{Definition of loads and boundary conditions}

In the knowledge path of heritage buildings, the geotechnical context assessment is fundamental for the evaluation and modeling process of the boundary conditions and the loads interacting with the referred structure (MIBAC, 2017; Vandesande \& Van Balen, 2018; Ioannides et al., 2016). The considered loads acting on the building are the dead loads of structural elements and the lateral loads due to the presence of the soil on three partially buried lateral façades. The weight contribution of non-structural elements is simplified by equivalent vertical loads. Such loads are introduced in the H-BIM workflow through Revit $^{\oplus}$. As previously mentioned, the contribution of the soil was simplified in terms of horizontal soil actions, that are modeled in Robot $^{\oplus}$, since it allows for the creation of triangular horizontal loads. Such load represents the hypothesis of at-rest earth pressures in which little or no movement is acceptable (Pradel, 1994), and the Jaky formulation was considered (Morgenstern \& Eisenstein, 1970). In addition, the retaining wall counteracting the soil action has a base thickness of $2.4 \mathrm{~m}$, confirming that rotation or movement is not allowed.

The assessment concerning the type of wall-beam and beam-beam connections of the structure was developed through visual inspection. The absence of rigid connections between the above-mentioned elements allows the supposition that rotations at each node are released. Beam elements and their connection type influence the results of the structural behavior analysis. The foundations were modeled in Revit ${ }^{\oplus}$, in which they are simplified as fixed constraints due to the rigid ground foundation assumptions (Clemente et al., 2012; Betti et al., 2016; Kilar \& Petrovčič, 2017). The simplifications are also validated by the visual inspection that showed how the vertical masonry elements are in contact with the soil, at a deeper level than the considered construction ground floor (Figure 10(b)).

\subsection{Linear elastic analysis}

In the structural assessment of historical constructions, linear analysis is always performed, prior to the application of more sophisticated approaches, in order to allow an overall understanding of the structural behavior, the range values and distributions of the loads and the mesh definition and calibration (Roca et al., 2010). A necessary condition for the linearity of a structural problem is that some characteristics of the system satisfy at the same time

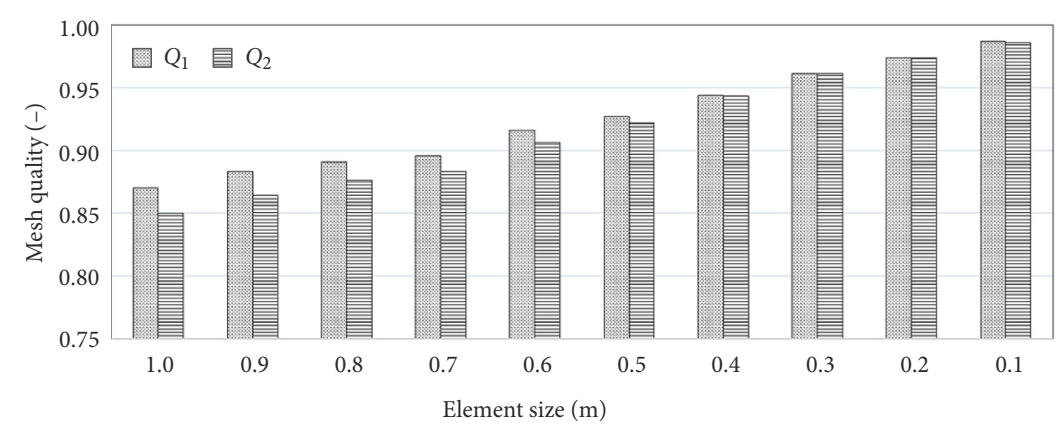

Figure 5. Evolution of the mesh quality dimensionless parameters $Q_{1}$ and $Q_{2}$ of the Coons mesh method according to the element size 
the following hypotheses, in terms of materials, geometry and boundary conditions. Geometric linearity has been assumed for structural behavior and linear elastic materials were assumed as well, the constraints of the structure are bilateral and do not depend on the entity of the acting loads (Del Piero, 1989; Roca et al., 2010). Such structural analysis consents to understanding of the structural global behavior and to hypothesize the causes of the different constructive configurations during time.

The results of the previous analyses were recorded in the control points selected on the north-east façade, which was the most affected by the restoration interventions during time (Figure 6). The information collected, such as the historical-critical analysis, the surveys, and the physical-mechanical characterization of the materials, were implemented in the architectural H-BIM model and used to create the structural H-BIM model.

The linear static analyses were focused on the evaluation and the comparison of two main parameters in the constrictive evolution phases: the out-of-plane top displacement and the base compressive stress. In Robot ${ }^{\circledR}$, the structural analysis is developed with the sparse method (Bank \& Douglas, 1993; Autodesk Inc., 2015a). The direct sparse solvers (SPDS) are computational techniques based on the decomposition of the matrix with a considerably smaller number of elements different from zero (Bank \& Douglas, 1993; Autodesk Inc., 2015a). This method solves the following linear equation system (Department of Aerospace Engineering Sciences, 2018) (Eqn (4)):

$$
[K]\{U\}=\{F\},
$$

where $[K]$ is the stiffness matrix, $\{U\}$ the displacement vector, $\{F\}$ the force vector of the system.

The modal analysis is elaborated through the Lanczos method (Koch, 2011; Autodesk Inc., 2012a) by the solution of the equation system of eigenvalue problems (Eqn (5)). The static loads of soil and the weight of non-structural elements are considered as masses of the dynamic system and considered in the following system:

$$
\left\{[K]-\omega_{i}^{2}[M]\right\}\left\{U_{i}\right\}=0
$$

where $[K]$ is the stiffness matrix of the structure, $[M]$ is the mass matrix of the structure, $\omega_{i}$ is the natural pulsation (natural frequency) of mode $i$ and $U_{i}$ is the eigenmode vector of mode $i$.

In each constructive phase, the vibration modes are selected as qualitative parameters that characterize and summarize the structural behavior in the two main direc- tions. The mode shapes are calculated in both directions to evaluate the stiffness variation caused by the several interventions on the masonry structure. They also allow the investigation of the influence of the different interventions over time.

\section{Results and discussion}

The results obtained in the proposed research are shown in this section. After the mesh refinement process of the FEM model, the modal analysis was developed to resume the global behavior in each constructive phase, in terms of overall stiffness. The static analyses were resumed through the evaluation of two main parameters, the top out-ofplane displacement, and the base compressive stress. Both analyses were developed to improve the knowledge path of the referred historical construction.

\subsection{Evolution of the structural behavior of the Quartel}

The proposed qualitative analysis of the evolution of structural behavior is developed to understand the constructive phases of historical construction. Furthermore, such analysis allows the supposition of possible reasons that led to the modification during time in case of lack of information in the knowledge path of the historical construction.

\subsubsection{Evolution of first vibration mode through the constructive phases}

The evolution of the global stiffness was evaluated through the analysis of the main modes of each model, according to the different construction phases. The results, resumed in Table 2, showed an increase in the natural frequency of the main modes in the transversal and longitudinal direction (Figure 7 ). In the following Table 2, some parameters are selected to describe different characteristics of each mode, $f$ and $T$ are respectively the frequency and the period of the vibration mode, $P M M$ is the representative mass percentage of the mode in the longitudinal $(X)$ and transversal $(Y)$ directions, $M$ is the total mass of the structure, $\Delta f$ and $\Delta M$ are the increases in terms of frequency and total mass, in relation to the previous model.

The modal analysis suggests how in each constructive phase the value of the frequencies increased despite the masses increasing as well. This result suggests how, in relation to the distribution of the masses along with the geometry of the construction, the structural global stiffness increased (Figure 7 and Table 2). The increase of the frequencies of the main modes occurs mainly in

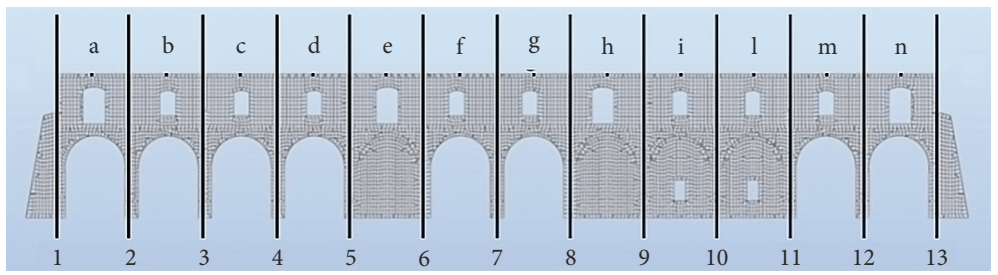

Figure 6. Definition of axes and control-points in the finite element model in the north-east façade 
First transversal mode

a) Phase 1: As-designed configuration $\quad 3.01 \mathrm{~Hz}$

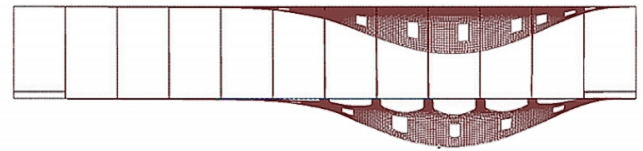

b) Phase 2: Central masonry element

$3.15 \mathrm{~Hz}$

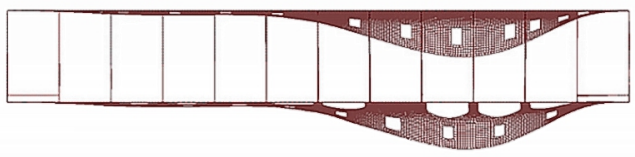

c) Phase 3: Buttresses

$3.23 \mathrm{~Hz}$

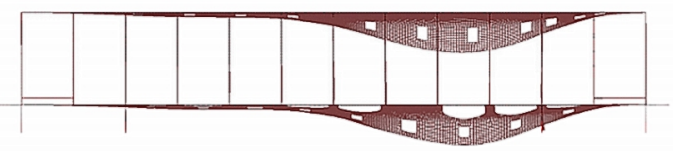

d) Phase 4: As-built configuration

$3.34 \mathrm{~Hz}$

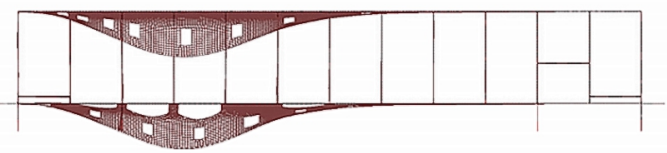

First longitudinal mode

a) Phase 1: As-designed configuration

$3.60 \mathrm{~Hz}$

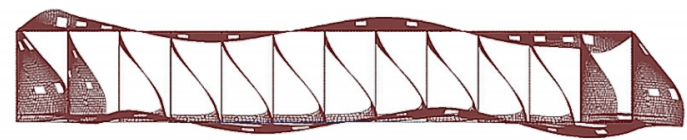

b) Phase 2: Central masonry element

$3.56 \mathrm{~Hz}$

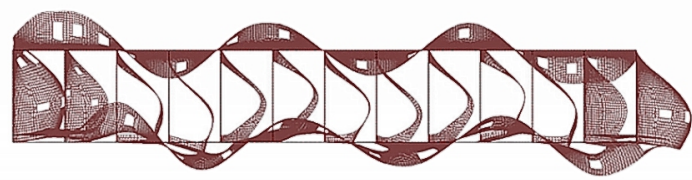

c) Phase 3: Buttresses

$3.75 \mathrm{~Hz}$

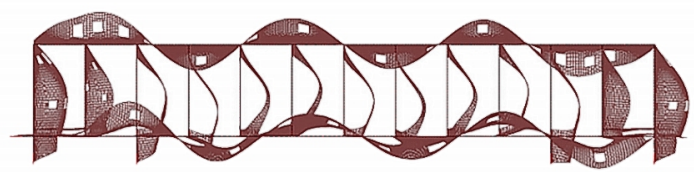

d) Phase 4: As-built configuration

$3.29 \mathrm{~Hz}$

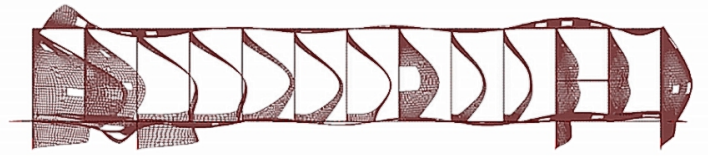

Figure 7. Evolution of the most representative transversal and longitudinal mode according to the constructive phases:

(a) 'as-designed' project; (b) introduction of the central masonry element; (c) introduction of the buttresses; (d) 'as-built' project

Table 2. Modal parameters according to the constructive phases

\begin{tabular}{|l|c|c|c|c|c|c|}
\hline \multicolumn{1}{|c|}{ Transversal direction } & $f(\mathrm{~Hz})$ & $T(\mathrm{~s})$ & $P M M-Y(\%)$ & $M(\mathrm{~kg})$ & $\Delta f(\%)$ & $\Delta M(\%)$ \\
\hline Phase 1 & 3.01 & 0.33 & 17.84 & 3593349.70 & - & - \\
\hline Phase 2 & 3.15 & 0.32 & 21.11 & 3829560.79 & 4.65 & 6.57 \\
\hline Phase 3 & 3.23 & 0.31 & 20.89 & 4023393.51 & 2.54 & 5.06 \\
\hline Phase 4 & 3.34 & 0.30 & 15.67 & 4219425.75 & 3.41 & 4.87 \\
\hline Longitudinal direction & $f(\mathrm{~Hz})$ & $T(\mathrm{~s})$ & $P M M-X(\%)$ & $M(\mathrm{~kg})$ & $\Delta f(\%)$ & $\Delta M(\%)$ \\
\hline Phase 1 & 3.60 & 0.28 & 31.82 & 3593349.70 & - & - \\
\hline Phase 2 & 5.56 & 0.18 & 22.76 & 3829560.79 & 54.44 & 6.57 \\
\hline Phase 3 & 5.75 & 0.17 & 10.21 & 4023393.51 & 3.42 & 5.06 \\
\hline Phase 4 & 6.29 & 0.16 & 28.71 & 4219425.75 & 9.39 & 4.87 \\
\hline
\end{tabular}

the longitudinal direction when the thick central masonry slope-shaped element is introduced, $\Delta M 6.57 \%$ and $\Delta f$ $54.44 \%$. This is due to the thick section of the masonry element that increases the stiffness in the same direction. A comparison is realized between the four phases, thus describing the constructive evolution. The identification of the first mode shape for each constructive phase allows the understanding of how the interventions of the masonry structures increase the global stiffness, modifying the mode shapes (Figure 7). As the first modes always appear in the transversal direction (Figure 7), it is considered as the weakest one.

The modification of the longitudinal modal shapes between the constructive Phases 1 and 2 (Figure $7 \mathrm{a}$ and
Figure 7b) suggests also that the dynamic behavior of the construction was modified by the introduction of the slope-shaped central masonry element. In the same direction, the buttresses (Phase 3 ) do not modify the mode shape but cause a frequency increase $\Delta f 2.54 \%$, despite a $\Delta M 5.06 \%$, meaning a possible stiffness increase. The introduction of thick masonry walls, under the arches in the right part of the structure, lead to a $\Delta f 3.41 \%$, modifying the first transversal mode shape (Phase 4 ). The 'as-built' configuration (Phase 4) shows how the introduction of masonry walls in the right part leads to an asymmetrical behavior in terms of mode shape, and consequently in terms of frequency, distribution of the masses, and stiffness. 


\subsubsection{Out-of-plane displacement}

The top out-of-plane displacements obtained from the analysis of the permanent loads are presented in Figure 8. It is possible to understand how the horizontal soil action is the main cause of the lateral displacement (Figure 8). On the other hand, the timber structures of the roof introduce lateral loads in the vertical masonry structure (Pereira, 2007). In the main façade, these two types of loads have the same direction, increasing the lateral displacement of the construction. In the opposite façade, south-west, these loads have opposite direction. The introduction of the central masonry element does not reduce considerably the out-of-plane top displacement (Figure 8b). The introduction of the buttresses - axes $3^{\text {rd }}$ and $11^{\text {th }}-$ reduced the out-of-plane displacement in the transversal direction (Figure 8c). In the 'as-built' constructive configuration, walls, introduced in the lower level of the right part of the construction, reduced the out-of-plane displacement, in the right part of the façade (Figure $8 \mathrm{~d}$ ). Consequently, the 'as-built' configuration led to an asymmetrical behavior of the structure, confirming the results of the modal analysis.

The analyses of the different constructive phases allow the understanding of how the restorations affected the global structural behavior of the construction. The interventions modified the configuration of the northeast façade. For these reasons, focusing on the structural response of this façade in the main constructive phases was interesting. In the 'as-designed' configuration, the out- of-plane displacement reaches the maximum values of the north-east façade, in the control point $d$ and $i$ (Figure 6 and Figure 8a). As expected, the buttresses, introduced where the high displacement values were reached at $3^{\text {rd }}$ and $11^{\text {th }}$ axes, reduced the out-of-plane displacements in these points (Figure $8 \mathrm{c}$ ). According to the simplification of the main constructive phases, the 'as-built' configuration led a displacement reduction in the right side of the façade (Figure 8d). The results pointed out that the modification of the construction improved the structural behavior in terms of top out-of-plane displacement, particularly in the buttresses - axes $3^{\text {rd }}$ and $11^{\text {th }}$ - of the façade. On the other hand, the 'as-built' structure (Figure 8d) shows a high level of asymmetry due to the introduction of thick masonry walls under the arches on the right part of the construction, causing an asymmetric response to the acting loads. The results of the out-of-plane displacement confirm the main deformation configuration suggested by the first mode shape of the structure in the transversal direction.

\subsubsection{Base compressive stress}

The compressive stresses achieved at the base of each axis of the north-east facade are presented in Figure 9. The introduction of the central masonry element (Phase 2) caused a stress reduction, relating to the 'as-designed' configuration (Phase 1), of $43 \%$ in the central column on the $7^{\text {th }}$ axis (Figure 9). This intervention also reduced the stresses in the north-east façade, from axis $4^{\text {th }}$ to axis $10^{\text {th }}$. a) Phase 1: As-designed configuration $\quad-0.5 \mathrm{~cm} \quad \stackrel{\leftrightarrow}{\longrightarrow}$

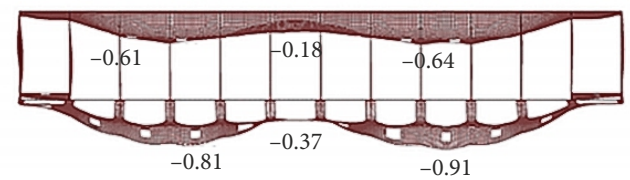

c) Phase 3: Buttresses

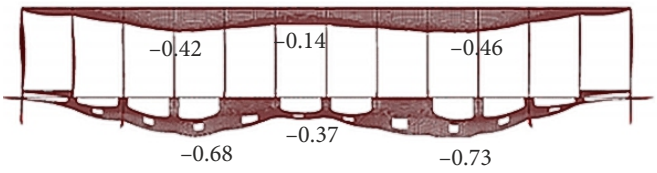

b) Phase 2: Central masonry element

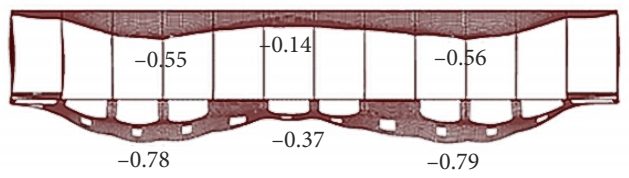

d) Phase 4: As-built configuration

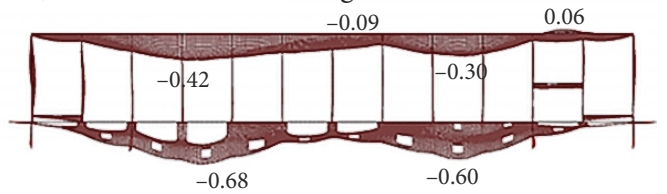

Figure 8. Out-of-plane top displacement $(\mathrm{cm})$ of the north-east façade according to the constructive evolution: (a) 'as-designed' project; (b) the introduction of the central masonry element; (c) the introduction of the buttresses; (d) 'as-built' project

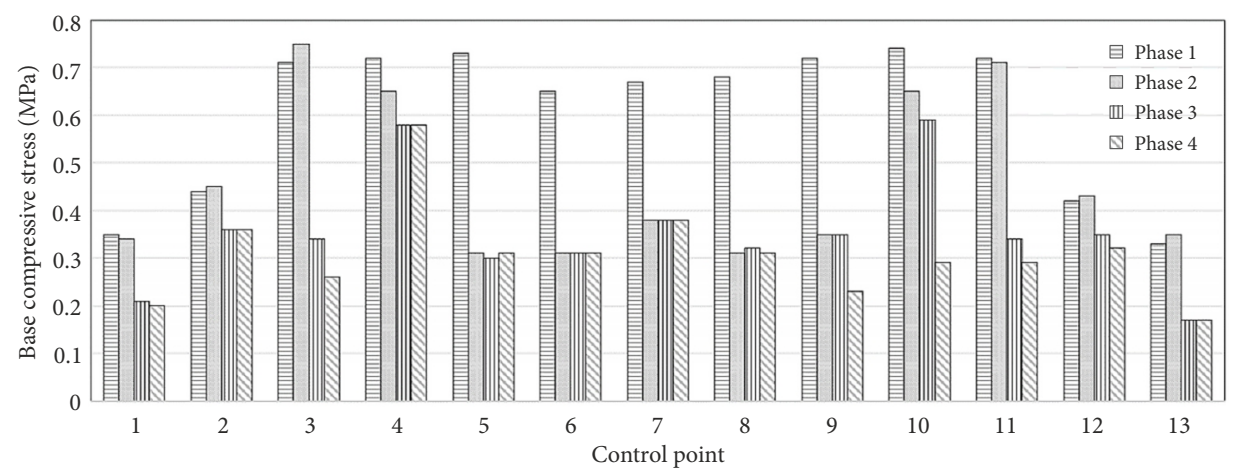

Figure 9. Base compressive stress ( $\mathrm{MPa})$ in the control points of the north-east façade according to the constructive evolution 
a)

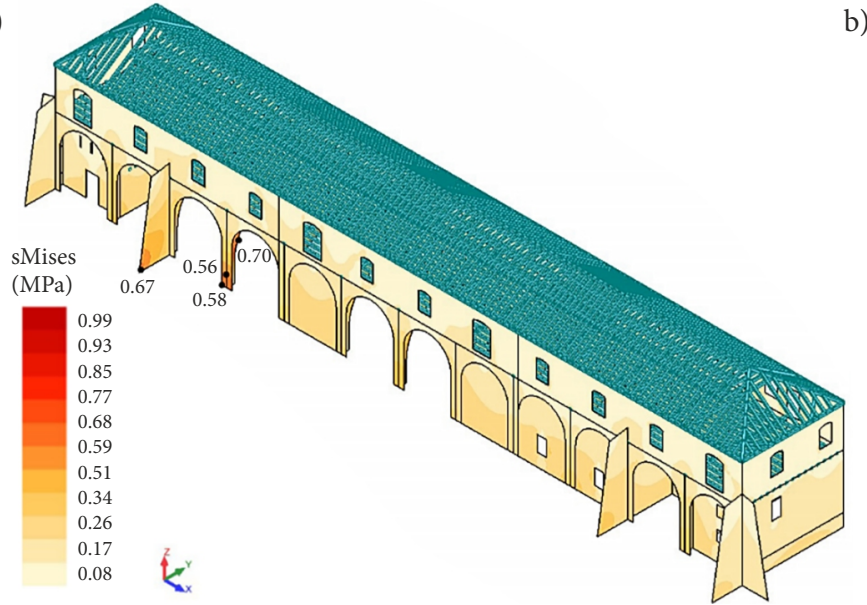

b)

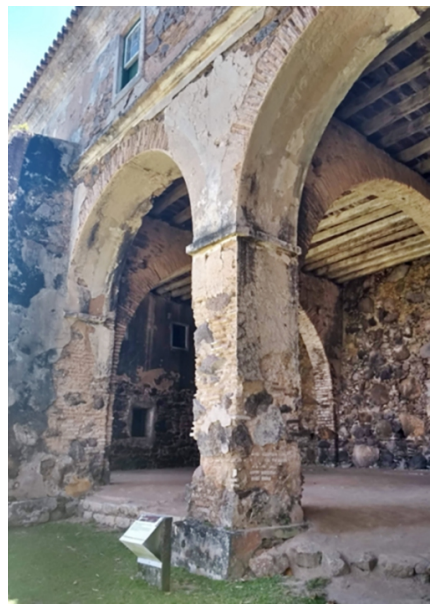

Figure 10. Stress distribution: (a) in the 'as-built' configuration and (b) damage on the column of the north-east

At the same time, it caused an increase in the compressive stress at the base of the 3rd axis. The introduction of the buttresses (Phase 3 ) caused a reduction respectively of $55 \%$ and $52 \%$ at the base of the axes $3^{\text {rd }}$ and $7^{\text {th }}$ (Figure 9 ).

The analysis of the base compressive stress in the 'asbuilt' masonry structures (Phase 4) confirmed the asymmetrical structural behavior in the 'as-built' configuration. The introduction of the central masonry element and the buttresses reduced both the top out-of-plane displacements and the compressive stresses of the structure in its main façade. While the thick masonry walls introduced in the 'as-built' configuration (Figure 4d) reduced both displacements (Figure 8) and stresses (Figure 9), they caused an asymmetrical global structural response of the masonry structures, concentrating the stresses on the left side of the building, particularly in the arch and in the column in the axis 4 (Figure 10). These results are confirmed by the current state of the building, where cracks and damages appear in the above-mentioned structural elements (Figure 10b).

The results suggest that the constructive modifications, summarized in the Phases 1, 2 and 3 (Figure 4) were made to improve the global structural behavior, aiming to counteract the horizontal actions, including the loads due to the soil. Those assumptions suggest how horizontal actions must be carefully considered in the structural assessment developed in any future restoration planning. Indeed, they were possibly the main reasons for the structural interventions made. On the other hand, the results obtained for the 'as-built' configuration (Figure 8d and Figure 9) suggest that the introduction of longitudinal and transversal masonry walls modification was probably made according to functional requirement, as already pointed out in Section 2.1, in the spatial distribution of the lower level of the building, neglecting the structural consequences of the construction. Regarding the wooden horizontal elements, they improve the stiffness and the box behavior of the building, but they do not reduce the asymmetrical behavior, in terms of vibration modes, stresses, and displacements. Furthermore, in the 'as-built' configuration base compressive stresses reach values that are far from the considered average compressive strength of the masonry structures $(1.40 \mathrm{MPa})$. Since the results obtained from the static analysis are sufficiently distant from this value, it means that the linear static analysis is consistent with a qualitative interpretation of the structural behavior.

\section{Conclusions}

The application of the H-BIM workflow on the study case of the Quartel da Tropa shows how the proposed multidisciplinary approach allows the understanding of the constructive phase evolution of a historical building and the possible reasons that caused modifications during the lifecycle of such construction. The obtained results lead to the following conclusions:

- the proposed workflow has the followings steps: historical-critical analysis, material and soil characterization, data organization through Historical Building Information Modeling (H-BIM), qualitative dynamic and static structural analysis, elaboration of the results. Such an approach allows the creation of a structural model from the architectural model with fewer uncertainties and less simplification, improving the knowledge path of historical constructions. The historical-critical analysis and the H-BIM allow the managing and presenting of the information useful to the understanding of the constructive phase evolution of a historical building;

- the lack of information about the physical and mechanical characteristics increases the level of uncertainties in the structural analysis, while not representing the real behavior of the building, the linear analysis provides suggestions about the overall structural behavior of the construction;

- the analysis of the constructive evolution allows the defining of how the restoration interventions modi- 
fied the structural behavior of a building and it is useful to understand the reasons for the different modifications during time.

Furthermore, presenting the results related to the case study helps to show how the proposed approach is applied to the heritage built. The results of the modal analysis show how frequencies of the main modes, in both directions, increased in each constructive phase, also suggesting an increase in the global stiffness of the structure. Such results suggest that:

- the structural interventions modified the global behavior of the construction, in terms of displacement, stresses, and stiffness, and in the 'as-built' configuration introduced an asymmetrical global behavior in the masonry structures;

- despite the wooden horizontal elements improves the stiffness and the box behavior of the building, they do not reduce the asymmetrical behavior, in terms of vibration modes, stresses, and displacements;

- the structural assessment, fundamental for future interventions, should carefully consider the horizontal loads acting on the structure and the contribution of the wooden structures. The results also demonstrate that the functional modification of the building should not neglect their effects in the overall structural behavior.

\section{Acknowledgements}

The authors would like to thank Professor Carmelo Gentile - Department of Architecture, Built Environment and Construction Engineering of the Politecnico di Milano who provided insight and expertise that greatly improved the proposed research paper. This project has been funded with support of the European Commission. This publication reflects the view only of the authors, and the Commission cannot be held responsible for any use which may be made of the information contained therein - ELARCH program (Project Reference number 552129-EM-1-20141-IT-ERA MUNDUS-EMA21). This study was also financed in part by the Coordenação de Aperfeiçoamento de Pessoal de Nivel Superior - Brazil (CAPES) - Finance Code 001.

\section{Funding}

This work was supported by the European Commission under Grant 552129-EM-1-2014-1-IT-ERA MUNDUSEMA21; it was also supported by the Coordenação de Aperfeiçoamento de Pessoal de Nível Superior - Brazil (CAPES) - Finance Code 001.

\section{Author contributions}

Alfredo Calì (AC) is the main author of this paper, which is associated to his $\mathrm{PhD}$ research. Prof. Poliana Dias de Moraes (PDM) and Prof. Ângela do Valle (ÂV) are the supervisors of the related $\mathrm{PhD}$ thesis. AC, PDM and $\hat{\mathrm{AV}}$ conceived the study. AC was responsible for the design and development of the data collection and analysis. AC wrote the first draft of the article. PDM and ÂV supervised the article and the data interpretation.

\section{Disclosure statement}

Authors declare to have not any competing financial, professional, or personal interests from other parties.

\section{References}

ABNT. (2004). N6118-2003. Norma Brasileira. Projeto de estruturas de concreto - Procedimento [Design of structural concrete - Procedure]. Rio de Janeiro (in Portuguese).

Arash, S. (2012). Mechanical properties of masonry samples for theoretical modelling. In 15th International Brick and Block Masonry Conference. Florianópolis, Brazil.

Antonopoulou, S., \& Bryan, P. (2017). BIM for heritage: developing a historic building information model. Historic England, Swindon.

Autodesk, Inc. (2012a). Robot - Calculations: Lanczos method (Dynamic analysis). https://knowledge.autodesk.com/support/ robot-structural-analysis-products/learn-explore/caas/documentation/RSA/2013/ENU/filesROBOT/GUID-9A509DAF7A96-4B90-8223-6C2413BCC326-htm.html?st=lanczos

Autodesk, Inc. (2012b). Integrating Revit structure and Robot structural analysis professional workflows. https://www.cadstudio.cz/dl/Linking_Autodesk_Revit_Revit\%20Structure_and_ Robot_Structural_Analysis_Professional-Whitepaper.pdf

Autodesk, Inc. (2015a). Robot - Calculations: Sparse method. Robot structural analysis Products. Autodesk knowledge network. https://knowledge.autodesk.com/support/robotstructural-analysis-products/learn-explore/caas/CloudHelp/ cloudhelp/2015/ENU/Robot/files/GUID-0C1A369E-5DED4C23-AE5D-8929D62F5A93-htm.html

Autodesk, Inc. (2015b). Calculation of mesh quality coefficient of finite elements. https://knowledge.autodesk.com/support/ robot-structural-analysis-products/learn-explore/caas/CloudHelp/cloudhelp/2015/ENU/Robot/files/GUID-C99501F6BCCB-458F-9CA1-87AD1876889F-htm.html

Bank, R. E., \& Douglas, C. C. (1993). Sparse matrix multiplication package (SMMP). Advances in Computational Mathematics, 1(1), 127-137. https://doi.org/10.1007/BF02070824

Barazzetti, L., Banfi, F., Brumana, R., Oreni, D., Previtali, M., Roncoroni, F., \& Schiantarelli, G. (2015). BIM from laser clouds and finite element analysis: combining structural analysis and geometric complexity. The International Archives of the Photogrammetry, Remote Sensing and Spatial Information Sciences, 40(5-W4), 345-350.

https://doi.org/10.5194/isprsarchives-XL-5-W4-345-2015

Bathe, K. J. (2016). Finite element procedures for solids and structures. Nonlinear analysis. MIT Center for Advanced Engineering Studies.

Betti, M., Galano, L., \& Vignoli, A. (2016). Finite element modelling for seismic assessment of historic masonry buildings. In S. D'Amico (Ed.), Earthquakes and their impact on society (pp. 377-415). Springer. https://doi.org/10.1007/978-3-319-21753-6_14

Biagini, C., Capone, P., Donato, V., \& Facchini, N. (2016). Towards the BIM implementation for historical building restoration sites. Automation in Construction, 71, 74-86.

https://doi.org/10.1016/j.autcon.2016.03.003 
Bruno, S., De Fino, M., \& Fatiguso, F. (2018). Historic building information modelling: performance assessment for diagnosis-aided information modelling and management. Automation in Construction, 86, 256-276.

https://doi.org/10.1016/j.autcon.2017.11.009

Clemente, P., Bontempi, F., \& Boccamazzo, A. (2012). Design and optimization of base isolated masonry buildings. In $15^{\text {th }}$ World Conference on Earthquake Engineering (15WCEE). Lisbon, Portugal.

Calì, A., do Valle, Â., \& de Moraes, P. D. (2019). Building information modeling and structural analysis in the knowledge path of a historical construction. In R. Aguilar, D. Torrealva, S. Moreira, M. A. Pando, \& L. F. Ramos (Eds), Structural analysis of historical constructions (pp. 2071-2079). Springer. https://doi.org/10.1007/978-3-319-99441-3_222

Carvalho, J., Ortega, J., Lourenço, P. B., Ramos, L. F., \& Roman, H. (2014). Safety analysis of modern heritage masonry buildings: Box-buildings in Recife, Brazil. Engineering Structures, 80, 222-240. https://doi.org/10.1016/j.engstruct.2014.09.004

Chi, H. L., Wang, X., \& Jiao, Y. (2015). BIM-enabled structural design: impacts and future developments in structural modelling, analysis and optimization processes. Archives of Computational Methods in Engineering, 22(1), 135-151.

https://doi.org/10.1007/s11831-014-9127-7

Coons, S. A. (1967). Surfaces for computer-aided design of space forms (No. MAC-TR-41). Massachusetts Institute of Technology. https://doi.org/10.21236/AD0663504

Crespi, P., Franchi, A., Ronca, P., Giordano, N., Scamardo, M., Gusmeroli, G., \& Schiantarelli, G. (2015). From BIM to FEM: the analysis of an historical masonry building. WIT Transactions on the Built Environment, 149, 581-592. https://doi.org/10.2495/BIM150471

Del Piero, G. (1989). Constitutive equation and compatibility of the external loads for linear elastic masonry-like materials. Meccanica, 24(3), 150-162.

https://doi.org/10.1007/BF01559418

Department of Aerospace Engineering Sciences. (2018). 'Solving FEM Equations'. In University of Colorado at Boulder (Ed.), Introduction to finite element methods (ASEN 5007). https:// www.colorado.edu/engineering/CAS/courses.d/IFEM.d/ IFEM.Ch26.d/IFEM.Ch26.pdf

Dore, C., Murphy, M., McCarthy, S., Brechin, F., Casidy, C., \& Dirix, E. (2015). Structural simulations and conservation analysis-historic building information model (HBIM). The International Archives of Photogrammetry, Remote Sensing and Spatial Information Sciences, 40(5/W4), 351-357. https://doi.org/10.5194/isprsarchives-XL-5-W4-351-2015

Eastman, C., Teicholz, P., Sacks, R., \& Liston, K. (2011). BIM handbook: A guide to building information modeling for owners, managers, designers, engineers and contractors. John Wiley $\&$ Sons.

Ferrito, T., Milosevic, J., \& Bento, R. (2016). Seismic vulnerability assessment of a mixed masonry-RC building aggregate by linear and nonlinear analyses. Bulletin of Earthquake Engineering, 14(8), 2299-2327.

https://doi.org/10.1007/s10518-016-9900-0

Gentile, C., \& Saisi, A. (2007). Ambient vibration testing of historic masonry towers for structural identification and damage assessment. Construction and Building Materials, 21(6), 13111321. https://doi.org/10.1016/j.conbuildmat.2006.01.007

Gentile, C., Saisi, A., \& Cabboi, A. (2015). Structural identification of a masonry tower based on operational modal analysis. International Journal of Architectural Heritage, 9(2), 98-110. https://doi.org/10.1080/15583058.2014.951792
Gesualdo, A., \& Nunziante, L. (2005). Omogeneizzazione di murature storiche. In Proceedings XVII National Congress AIME$T A$. Florence, Italy (in Italian).

Hacıefendioğlu, K., Demir, G., \& Alpaslan, E. (2016). Determination of modal parameters of historical masonry minarets by using operational modal analysis. In Proceedings of the World Congress on Civil, Structural, and Environmental Engineering (CSEE'16). Prague, Czech Republic.

https://doi.org/10.11159/icsenm16.104

Ho-Le, K. (1988). Finite element mesh generation methods: a review and classification. Computer-Aided Design, 20(1), 27-38. https://doi.org/10.1016/0010-4485(88)90138-8

Katili, I. (1993). A new discrete Kirchhoff-Mindlin element based on Mindlin-Reissner plate theory and assumed shear strain fields-part I: An extended DKT element for thickplate bending analysis. International Journal for Numerical Methods in Engineering, 36(11), 1859-1883.

https://doi.org/10.1002/nme.1620361106

Kilar, V., \& Petrovčič, S. (2018). Seismic rehabilitation of masonry heritage structures with base-isolation and with selected contemporary strengthening measures. International Journal of Safety and Security Engineering, 7(4), 475-485. https://doi.org/10.2495/SAFE-V7-N4-475-485

Koch, E. (2011). The Lanczos method. In E. Pavarini, E. Koch, D. Vollhardt, \& A. Lichtenstein (Eds), The LDA+ DMFT approach to strongly correlated materials. Reihe Modeling and Simulation. Lecture Notes of the Autumn School 2011.

Kolcun, A. (1999). The quality of meshes and FEM computations. In The 7th International Conference in Central Europe on Computer Graphics, Visualization and interactive Digital Media '99 (pp. 100-105).

Geotechnical Mapping Laboratory of Federal University of Santa Catarina. (2018). Geothecnical experimental results of Florianópolis soils. Florianópolis, Brazil.

Pereira, R. L. (2007). Estruturas de coberta da Arquitetura religiosa em Pernambuco tipologia, patologia e intervenções. AERPA.

Ioannides, M., Fink, E., Brumana, R., Patias, P., Doulamis, A., Martins, J., \& Wallace, M. (Eds.). (2016). Digital heritage. Progress in cultural heritage: Documentation, preservation, and protection. In 6th International Conference, EuroMed 2016, Nicosia, Cyprus.

Mastrodicasa, S. (2012). Dissesti statici delle strutture edilizie $\left(9^{\text {th }}\right.$ ed.). Hoepli (in Italian).

Magenes, G., \& Menon, A. (2009). A review of the current status of seismic design and assessment of masonry buildings in Europe. Journal of Structural Engineering (Madras), 35(6), 247-256.

Meli, R., \& Peña, F. (2004). On elastic models for evaluation of the seismic vulnerability of masonry churches. In Structural Analysis of Historical Constructions (pp. 1121-1131). Padova, Italy.

Morgenstern, N. R., \& Eisenstein, Z. (1970). Methods of estimating lateral loads and deformations. In Lateral Stresses in the Ground and Design of Earth-Retaining Structures (pp. 51-102). ASCE.

Murphy, M. (2012). Historic building information modelling (HBIM): For recording and documenting classical architecture in Dublin 1700 to 1830 (Doctoral dissertation). Department of Civil, Structural and Environmental Engineering, Trinity College, Dublin, Ireland.

NTC 2008. (2009). Norme tecniche per le costruzioni. Decreto Ministeriale 14 Gennaio 2008.

MIBAC. (2017). Guidelines for evaluation and mitigation of seismic risk to cultural heritage (Directive of the Prime Minister, 12/10/2007, G.U. n.24 of 29/1/2008). 
Oreni, D., Brumana, R., Della Torre, S., \& Banfi, F. (2017). Survey, HBIM and conservation plan of a monumental building damaged by earthquake. The International Archives of the Photogrammetry, Remote Sensing and Spatial Information Sciences, 42(5/W1), 337-342. https://doi.org/10.5194/isprs-archives-XLII-5-W1-337-2017

Pocobelli, D. P., Boehm, J., Bryan, P., Still, J., \& Grau-Bové, J. (2018). BIM for heritage science: a review. Heritage Science, 6(1), 30. https://doi.org/10.1186/s40494-018-0191-4

Pradel, D. (1994). Distribution des pressions actives dans les sols cohesifs [Active pressure distribution in cohesive soils]. In Proceedings of XIIIICSM FE (pp. 795-798). New Delhi, India.

Provatidis, C. G., \& Kanarachos, A. E. (2000). On the use of Coons' interpolation in CAD/CAE applications. In M. Mastorakis (Ed.), Systems and control: Theory and applications (pp. 343-348). World Scientific and Engineering Society Press.

ReLUIS. (2010). Linee guida per il rilievo, lanalisi ed il progetto di interventi di riparazione e consolidamento sismico di edifici in muratura in aggregato (in Italian).

Roca, P., Cervera, M., \& Gariup, G. (2010). Structural analysis of masonry historical constructions. Classical and advanced approaches. Archives of Computational Methods in Engineering, 17(3), 299-325. https://doi.org/10.1007/s11831-010-9046-1

Rocco Lahr, F. A., Christoforo, A. L., Chahud, E., Branco, L. A. M. N., Battistelle, R. A., \& Valarelli, I. D. (2015). Poisson's ratios for wood species for structural purposes. Advanced Materials Research, 1088, 690-693.

https://doi.org/10.4028/www.scientific.net/AMR.1088.690

Ross, R. J. (2010). Wood handbook: wood as an engineering material. USDA Forest Service, Forest Products Laboratory. https://doi.org/10.2737/FPL-GTR-190

Terezo, R. F. (2005). Avaliação das Estruturas de Madeira do Quartel da Tropa da Fortaleza da Ilha de Anhatomirim. Florianópolis, Brazil: Grupo Interdisciplinar de Estudos de Madeira - GIEM. http://fortalezas.org/midias/arquivos/3167.pdf (in Portuguese).

Tonera, R., \& Fragoso, M. P. (2013). The World fortifications database and his contributions to tourism as a guide social development. Caderno Virtual de Turismo, 13, 53-64.

Vandesande, A., \& Van Balen, K. (2018). Innovative built heritage models based on preventive and systemic approaches. In A. Vandesande \& K. Van Balen (Eds), Innovative built heritage models (pp. 3-10). CRC Press. https://doi.org/10.1201/9781351014793-1

Volk, R., Stengel, J., \& Schultmann, F. (2014). Building Information Modeling (BIM) for existing buildings - Literature review and future needs. Automation in Construction, 38, 109-127. https://doi.org/10.1016/j.autcon.2013.10.023

Zenid, G. J. (2009). Madeira: uso sustentável na construção civil. Instituto de Pesquisas Tecnológicas (in Portuguese).

Zienkiewicz, O. C., \& Taylor, R. L. (2000). The finite element method. Volume 2: Solid mechanics. Butterworth-Heinemann. 